\author{
Military Technical College \\ Kobry El-Kobbah, \\ Cairo, Egypt
}

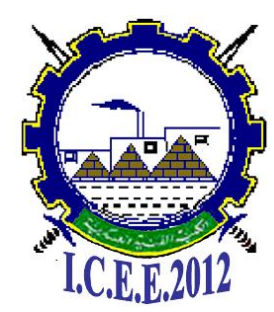

$6^{\text {th }}$ International Conference

on

Chemical \& Environmental

Engineering

29 -31 May, 2012.

\title{
CBTC-2 \\ BIOLOGICAL AGENTS: THREATS AND COUNTERMEASURES
}

\author{
Ashraf R.S. Shoeib ${ }^{*}, \mathrm{PhD}$

\begin{abstract}
:
\end{abstract}
The appearance of a new or reemerging infectious disease has global implications. During the past 20 years, over 30 new lethal pathogens have been identified. The emergence of severe acute respiratory syndrome (SARS) which jumped the species barrier from animals to humans and rapidly spread to 29 countries in less than 90 days. SARS or influenza appears to be occurring with increasing frequency and with a greater potential for serious consequences. A classic example of biological agent threats is the pandemic influenza where it first appeared in 1918 as the Spanish flu struck which in less than 1 year, this virus was able to spread globally and kill an estimated 40 million people. Locally, the more recently threats of influenza is H5N1 strain of avian flu, known as bird flu, appeared in Egypt in February 2006, and the poultry industry has been in a critical situation ever since as the government pursues its efforts to eradicate the disease. After avian flu, Egypt began fears from swine flu. The Egyptian government has decided to slaughter the nation's 300,000 pigs to prevent the spread of swine flu, and the health ministry has reportedly put all hospitals and quarantine center on alert to slow the spread of the virus in Egypt. The most recent outbreak is that of the foot and mouth disease (FMD) which appeared this year and spreads suddenly allover Egypt and infects about 100.000 Egyptian cattle and about one tenth of the suspected infected farm population has already died. The analysis showed that it is a new strain affects cloven-hooved animals such as cows, sheep, and pigs. It does not spread to humans, but it does render animal milk and meat unfit for consumption, threatening regional food supplies and the livelihood of the farmers who depend on animal husbandry for their income. FMD is categorized as a Level A disease, which means it, is highly contagious and has a great effect on the world economy as far as international trade is concerned.

Many factors contribute to the emergence and epidemiologic clues of new diseases threats including environmental changes, global travel and trade, and genetic changes in infectious agents, host, or vector populations. Once a new disease is introduced into a suitable human population, it often spreads rapidly and affects the public health, and if the disease is severe, it may lead to social disruption, and cause severe economic impact. Also, emerging disease outbreaks may be difficult to distinguish from the intentional introduction of infectious diseases for biological purposes and natural origin. Therefore, determining who is at risk and making appropriate decisions regarding prophylaxis as well as other response measures in the civilian setting as protection from bioterrorism will require based on the tools of epidemiology, and countermeasures. The recommended countermeasures are the immunization for the population at risk as a prophylaxes' response, improvement of rapid and

* Environmental Research Division, National Research Center, 12311, El-Behoos St., Dokki, Cairo, Egypt 


\section{Military Technical College Kobry El-Kobbah, Cairo, Egypt}

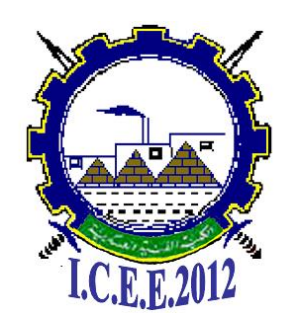

$6^{\text {th }}$ International Conference

Chemical \& Environmental Engineering 29 -31 May, 2012.

advanced diagnostic systems and facilities as standby for rapid detection and characterization, advancement of physical protection \& decontamination, and finally effective health organization and training. 